Marlowe, C. (1910) The Tragicall History of Doctor Faustus (1604). London : J. M. Dent \& Sons, Ltd., New York, E. P. Dutton \& Co. 44 p.

Shakespeare, W. (1990) King Lear. Ed. by K. Muir. The Arden Shakespeare. L., N. Y. 246 p.

Shakespeare, W. (1994) The Complete Works of William Shakespeare. Ware, Wordsworth Editions. 1263 p.

Shakespeare, W. (2016) Macbeth. Ed. by S. Clark and P. Mason. The Arden Shakespeare. Bloomsbury. $381 \mathrm{p}$.

Submission date: 30.08 .2018$.

Микеладзе Наталья Эдуардовна - доктор филологических наук, профессор кафедры зарубежной журналистики и литературы Московского государственного университета им. М. В. Аомоносова. Адрес: 125009, Россия, г. Москва, ул. Моховая, д. 9. Тел.: +7 (495) 629-37-80. Эл. адpec: fornatalia@bk.ru

Mikeladze Natalya Eduardovna, Doctor of Philology, Professor, Department of Foreign Journalism and Literature, Lomonosov Moscow State University. Postal address: 9, Mokhovaya St., Moscow, Russian Federation, 125009. Tel.: +7 (495) 629-37-80. Email: fornatalia@bk.ru

DOI 10.17805/zpu.2018.4.19

\title{
Философ в круге Марло: Уолтер Рэли и его трактат «Рассуждение о первоначальной и фундаментальной причине естественной, произвольной, необходимой и противоестественной войны»
}

\author{
В. В. МАРХИНИН
}

СУРГУТСКИЙ ГОСУДАРСТВЕННЫЙ УНИВЕРСИТЕТ

В статье рассматриваются взгляды Уолтера Рэли (1552-1618), английского политика, военного деятеля, мыслителя и поэта из круга Кристофера Марло. Предметом статьи является концепция войны, выработанная Рэли и сделанная им отправной точкой в анализе динамики общественной жизни в целом.

Рассматривается вопрос о характере возможного влияния социально-философских идей Рэли на мировоззрение Марло, анализируются идеи философских и политических трактатов Рэли, выявляется его место в разработке проблематики войны в философской литературе Ренессанса. Ключевые темы философского творчества Рэли - анализ феноменов войны, политических манипуляций, мотивов политического действия - созвучны сюжетам драматургии Марло, в то же время содержание его рассуждений коренным образом отличается от распространенного в литературе представления о вольнодумстве Марло. Влияние, которое могло испытывать мировоззрение Марло со стороны философских идей Рэли, по нашему мнению, имело направленность, типичную для христианского гуманизма в духе Эразма Роттердамского.

В своем трактате Рэли выступает с антивоенных позиций и стремится выявить предпосылки возникновения войн и условия, необходимые для их предотвращения. Среди войн он выделяет, во-первых, «естественные», связанные с борьбой за обладание жизненно важными ресурсами. Некоторые из них - неизбежны, другие - произвольны и, следова- 
тельно, могут быть предотвращены. Другой тип войн имеет предпосылки субъективного, социально-психологического порядка. Эти войны, среди которых гражданские и религиозные, противоестественны и чужды разумной природе человека. Особенность подхода Рэли к осмыслению войны состоит в синтезе идей макиавеллевского политического реализма и мировоззрения христианского гуманизма.

Текст доклада автора на Первой Всероссийской научной конференции «Кристофер Марло и его творчество в русской и мировой культуре: междисциплинарный взгляд», которая прошла в Москве 22-23 июня 2018 г.

Ключевые слова: философия Ренессанса; К. Марло; Уолтер Рэли; философия войны

\section{ВВЕАЕНИЕ}

Y олтер Рэли (1552-1618) является фигурой, хорошо известной любому, кто интересуется творчеством К. Марло. Традиционно Рэли, соединившего в своей биографии достоинства поэта, мыслителя и политического деятеля, связывают с деятельностью «Школы ночи», к которой, как предполагается, принадлежал и Марло. Теория о существовании этого кружка, с легкой руки Р. Парсонса известная также под именем «школы атеизма», долгое время рассматривалась как не вызывающая сомнений (Аживелегов, 1943; Clark, 1944). Позднее, примерно с середины XX в. (Reid, 2014: Электронный ресурс), она стала восприниматься более осторожно и даже скептически, поскольку ей явно недостает документальных подтверждений: единственное упоминание «школы» в конце XVI в. принадлежит иезуиту Р. Парсонсу, которого слишком легко заподозрить в стремлении представить английских придворных-протестантов безбожниками (Stone, 1905: 164-167), кроме того, как еще в 1951 г. показал в своей работе Э. Стратманн, она явно не стыкуется с идеями, которые в своих работах излагает Рэли (Strathmann, 1951). Вообще говоря, нет и стопроцентных документальных подтверждений личного знакомства Рэли и Марло, что, впрочем, учитывая общее состояние источников по биографиям той эпохи, не следует считать слишком уж весомым доводом против того, что оно имело место в действительности. Как бы то ни было, в каком-то виде это знакомство существовало, о чем свидетельствует известный литературный диалог, а версия о знакомстве двух знаменитостей Елизаветинской эпохи и о влиянии сэра Уолтера на мировоззрение юного Кита Марло не потеряла своей привлекательности вплоть до сегодняшнего дня.

Предметом статьи является концепция войны, выработанная Рэли и сделанная им отправной точкой в анализе динамики общественной жизни в целом.

\section{МИРОВОЗЗРЕНИЕ РЭАИ: ОСНОВНЫЕ ТЕКСТЫ И ИНТЕРПРЕТАЦИИ}

Вопрос о возможном характере этого влияния рассматривается обычно в контексте истории «вольнодумства» Марло: предполагается, что сформировалось оно под воздействием взглядов Рэли, перу которого принадлежат такие трактаты, как «Скептик», «О душе», «О церковной власти». В этой связи стоит держать в уме ряд принципиальных фактов творческой биографии Рэли. В общем, она делится на два больших периода: до и после его обвинения в заговоре, ареста и заключения в Тауэр в 1603 г. Bсе его тексты мировоззренческого содержания, имеющие на сегодняшний день сколько-нибудь надежную датировку, относятся ко второму периоду, т. е. ко времени после смерти Марло; не датированные тексты, такие, например, как «Скептик», «Причины великолепия и богатства городов», выглядят как явно незаконченные, черновые наброски; их содержание позволяет предполагать, что они могли быть попросту конспектами, не обязательно отражающими взгляды их составителя. Известно, на- 
конец, и то, что в состав канона Рэли, сформированного Аж. Мильтоном, его первым посмертным издателем, могли попасть тексты, приписанные Рэли ошибочно: так, давно доказано, что «Советник правительства» ( «Cabinet Council»), главный «макиавеллистский» текст, включенный в канон Мильтоном, не принадлежит Рэли (Strathmann, 1965); аналогичные сомнения высказываются и относительно другого яркого (и тоже «макиавеллистского») текста «Государь, или Максимы государства» (Evrigenis, 2013). Такая ситуация ставит перед исследователем оправданные вопросы: можно ли, и если да, то на каких основаниях, считать такого рода тексты источником влияния Рэли на Марло? Аействительно ли Рэли при жизни его предполагаемого юного друга и в момент наивысшего процветания имел те же взгляды, что он изложил в работах, написанных после смерти Марло и во время своего тринадцатилетнего тюремного заключения?

У вопроса о влиянии Рэли на Марло есть и другая сторона. Тезис о «вольнодумстве» предполагаемых друзей стал своего рода общим местом вопреки реальному состоянию источников наших знаний об их творческой биографии. Если о радикальном новаторстве Марло-драматурга недвусмысленно говорят его пьесы, то радикальные элементы его мировоззрения известны из вторых (и не слишком надежных) рук: из доносов и из показаний, данных под явным нажимом следствия, способного применять весьма суровые методы дознания. Сам Марло, как известно, богословских и философских трактатов не писал. Еще более шаткой выглядит версия о вольнодумстве Рэли: подтверждающие ее сведения происходят из точно таких же источников и находятся в явном противоречии с содержанием его прозаических (да и поэтических) произведений.

Упомянутый выше «Скептик» производит впечатление неоконченного конспекта: это весьма незамысловатое изложение аргументов пирронизма, в котором нет ничего похожего на попытку применить его полемические приемы против конвенциональных норм морали и религии. Трактат «О душе»написан с вполне христианских позиций и описывает душу как бессмертную нематериальную сущность, созданную Богом и несущую ответственность за дела человека. Рассуждение «О церковной власти» развивает тему, типичную для самой благонамеренной англиканской литературы: оно посвящено изобличению гордыни и коварства римских пап. Наконец, реализуя свой замысел «Истории мира», Рэли начинает с изложения ветхозаветной истории и выдерживает свое повествование в духе, который никак не позволяет заподозрить его в атеизме.

Тексты Рэли были популяризованы в годы противостояния Карла I с оппозиционными парламентариями будущим идеологом революции Аж. Мильтоном. Поднимаемые в этих текстах темы тирании, прерогатив парламента и короля, без сомнения, звучали в это время очень остро. Тем не менее в этих произведениях отсутствуют тираноборческие и антимонархические мотивы, типичные для таких теоретиков той эпохи, как Аж. Бьюкенен, Ф. Отман, Р. Парсонс, Т. Беза и др. Напротив, в них явным образом осуждается мятеж против законной власти, а монархия оценивается как лучшая из форм правления. Рэли известен как один из ранних английских читателей Макиавелли и его единомышленник. Первый элемент этой репутации вполне заслужен: Рэли действительно был внимательным читателем «Рассуждений» и «Государя»; второй же, скорее всего, преувеличен. Придерживаясь реалистического подхода к анализу политики и истории, Рэли явно не склонен изгонять из политики моральные нормы столь же бескомпромиссно, как это делает итальянский философ; не находится в его 
текстах и типичное для Макиавелли осуждение христианства и восхваление римской языческой морали. Оставляя за пределами этой краткой статьи поэтическое творчество Рэли, мы укажем лишь на то, что его философская лирика ("The Crosse of Christ», «My Last Will», «The Lie») демонстрирует не вольнодумство и не гедонизм вроде того, что приписывался Марло, а религиозное чувство, проникнутое духом contemptus mundi.

В показаниях, которые давались по ходу разбирательства об обстоятельствах смерти Марло, он предстает в облике бунтаря, ниспровергателя традиционных религиозных идей и представлений о морали и приличиях. Этот образ (отчетливо напоминающий персонажей его пьес) закрепляется в памяти поколений и продолжает ассоциироваться с Марло вплоть до сегодняшнего дня. Аействительно, интерпретация самых ярких персонажей Марло в качестве автопортрета темной стороны его личности обладает большой притягательной силой. С другой стороны, подвести надежную эмпирическую базу под эту, в общем-то «логичную», интерпретацию вряд ли возможно. В настоящей статье мы не рискнем делать какие-либо выводы относительно ее оправданности и ограничимся лишь следующим замечанием. Если мировоззрение Марло действительно соответствовало этим представлениям, Рэли вряд ли приложил руку к его формированию. Научиться атеизму, распущенности или «макиавеллизму», читая философские трактаты и стихотворения Рэли, чрезвычайно сложно.

Расхожая концепция «влияния Рэли на Марло», таким образом, представляется нам крайне сомнительной. Тем не менее сама по себе проблема соотношения взглядов этих авторов вполне актуальна. Марло и Рэли - вне зависимости от степени их знакомства - связаны принадлежностью к единому кругу духовных и интеллектуальных течений, их творчество имеет массу точек соприкосновения. В первую очередь эти точки соприкосновения локализуются в области трансформаций политического мировоззрения эпохи. Война между государствами, гражданская (религиозная) война, тирания, политическая мудрость и хитроумие, самостоятельность человека перед лицом сил, над которыми он не властен, - все это центральные темы творчества обоих писателей. Представляется очевидным, что расширение знаний об идеях Рэли, яркого и, к сожалению, недооцененного мыслителя, позволит расширить и горизонты понимания творчества Марло.

Настоящая работа посвящена одной из обозначенных выше общих для Рэли и Марло тем - теме войны, которая становится предметом трактата «Рассуждение о первоначальной и фундаментальной причине естественной, произвольной, необходимой и противоестественной войны» (далее «Рассуждение»).

Трактат был написан Рэли в ходе работы над «Историей мира» и окончен вскоре после выхода в свет ее первых частей, т. е. не ранее 1614 г.; при жизни автора не издавался. Текст трактата, который позднее вошел в канон и включался во все собрания сочинений, неоднороден и представляет собой довольно искусственное объединение двух самостоятельных произведений, слабо связанных по своей проблематике. Это, во-первых, собственно исследование феномена войны, во-вторых, упомянутое выше рассуждение о светской и церковной власти, вставленное в середину первого текста. Вопрос о том, кто был автором такой композиции - Рэли или его издатели, нуждается в дальнейшем изучении: известен и иной вариант их издания, предпринятый внуком Рэли в начале XVIII в.; там они совершенно оправданным образом даются как самостоятельные произведения (Ralegh, 1702). 


\section{«ЕСТЕСТВЕННЫЕ ВОЙНЫ», ИХ СВЯЗЬ С ПРИРОАОЙ}

\section{И ПОТРЕБНОСТЯМИ ЧЕАОВЕКА}

Рэли делает осмысление войны отправной точкой в развитии широкого спектра идей относительно генезиса общества и государства и логики общественных отношений в целом. Такой ход мысли выглядит как достаточно предсказуемый и логичный Аля него - опытного солдата и моряка, участника многочисленных сражений на суше и на море. Неожиданным образом Рэли, состоявшийся как политик и придворный именно благодаря войне, выступает в этой работе как ее противник. Война есть до некоторой степени неизбежное зло, но ее неизбежность не может рассматриваться в качестве оправдания: война «из всех человеческих дел является самым беззаконным [хотя и] имеет некоторую степень родства и близости с необходимостью закона: ни в законе, ни в войне не было бы нужды, если бы человек обладал достаточным благоразумием, чтобы заключать, каковы его обязанности и права, а также обладал бы способностью пунктуально исполнять то, что, как самому ему известно, является должным, и быть довольным тем, что имеет» (Ralegh, 1829: 254).

Война - манифестация неразумных страстей и пороков человеческой природы, и одновременно она есть «просто естественное состояние (state of nature), состояние людей вне общества, где все имеют равное право на все вещи, поскольку я пользуюсь своей жизнью, своим телом (substance), всем, что дорого мне, лишь до того времени, пока это мне позволяет кто-то более хитрый, более сильный, чем я, поскольку естественная совесть не сдерживает в достаточной мере грубые страсти людей, находящихся вне законов общества» (там же: 279). (Эта характеристика войны, вызывающая очевидные ассоциации с концепцией Гоббса, появляется у Рэли почти за четыре десятка лет до « Аевиафана»).

В чем же причина естественности такой беззаконной и губительной для человека практики? Рэли, как и позднее Гоббс, оценивал моральные достоинства естественного человека довольно пессимистически, но готовность людей участвовать в войне он связывает не с душевными качествами, а с экономическими потребностями людей. Война естественна, поскольку естественно стремление людей к материальному благополучию, ее фундаментальная предпосылка - борьба за землю и прочие экономические ресурсы, без которых невозможно само выживание.

«Если страна оказывается перенаселенной, возникает естественная необходимость избавиться от этого бремени, переложив его на других всеми правдами и неправдами, поскольку за исключением чумы, которая также чаще посещает людей, проживающих скученно, нет такого несчастья, которое сильнее, чем голод, толкает людей на отчаянные дела и презрение к смерти. Поэтому такая война, вызванная неисцелимой нуждой, может быть названа неизбежной или необходимой войной» (там же: 256). Борьба за место под солнцем наиболее ужасна по своим последствиям, «поскольку захватчики не могут удовлетворить себя иначе, чем искоренив или изгнав народ, на который они напали» (там же: 255). «Это подтверждается... например, саксами в Англии и арабами в Берберии. Что же происходит в этом случае с тем огромным множеством, которое покрывает части целых континентов? Конечно же, они умирают не от старости или от иных естественных причин, но из-за голода, эпидемий, от меча, удавки и тысячи иных бедствий. К тому же многие из них, вероятно, никогда и не появятся на свет, поскольку нехватка средств к пропитанию детей заставляет отказываться от брака, жениться на богатых старухах или ради выгоды заключать какой-то иной неравный или нездоровый брак, потому что бедность вопреки природе заставляет думать, что бесплодная жена - 
это не проклятие, а благодать» (там же: 258-259). Возникновение таких войн невозможно предотвратить, поскольку они вызываются, в конечном итоге, естественным приростом населения; людей, которых не в состоянии прокормить земля, государство будет вынуждено отправлять на завоевание (совсем пустой земли не бывает) колоний или, что случается чаще - на ограбление соседей, ведь «что может убедить могучий народ отправиться столь далеко, через моря, горы, пустыни и большие реки вместе с женами и детьми, если они (по крайней мере, как им самим кажется) имеют достаточно силы, чтобы заставить других возложить на себя бремя такого путешествия?» (там же: 255).

Вывод о взаимосвязи между демографическим ростом, дефицитом ресурсов и войнами будет подробно развит другим англичанином - Т. Мальтусом, концепцию которого Рэли предвосхищает в общих чертах. Впрочем, ход мысли, ведущий в направлении мальтузианства, Рэли делает не в одиночку, а, по всей видимости, с опорой на наработки Аж. Ботеро. Трактат этого итальянского экономиста и географа «О причинах величия городов» ( «Delle cause della grandezza delle citt?», 1588), видимо, послужил основой для наброска (конспекта?) Рэли «Причины великолепия и богатства городов» ( «Causes for Magnificence and Opulency of Cities»); об интересе английских читателей к работе итальянского мыслителя говорит, в частности, перевод его трактата, выполненный в 1606 г. (Botero, 1606). Предметом анализа Ботеро были меры по развитию торговли и производства, которые правительство способно принимать для обеспечения экономических интересов государства и для предотвращения того, что позднее было названо «мальтузианской ловушкой» (Murrey, 2006). Рэли также не чужд интерес к этой проблематике.

С экономическими проблемами - уже не целых сообществ, а отдельных сословий и индивидов - Рэли связывает предпосылки другой разновидности войны: естественной и при этом произвольной. Это война, вызванная нуждами паразитической части общества, аппетитами всевозможных «младших сыновей и младших братьев, у которых нет ни земли, ни иных средств к существованию в виде, например, торговли или другой полезной профессии; когда они не находят себе занятия, невозможно избежать того, чтобы все тело государства не было заражено жадностью этих злонравных членов.

В этом случае не поможет способность государства прокормить больше людей, чем в нем живет, и обеспечить из запасов значительное число нуждающихся.

Начнутся жалобы, которые встретят сочувствие, а затем начинается и ропот (поскольку люди всегда готовы винить правительство в бедах, причины которых им не известны), если правительство не решит удовлетворить нужду при помощи меча, обращенного на иностранцев» (Ralegh, 1829: 258).

К этому же разряду относятся жалобы купцов на действительные и мнимые обиды, которые нанесли им в чужих землях: «малейший ущерб от иностранцев они готовы терпеть в гораздо меньшей степени, чем более крупный убыток от вице-адмиралов, таможенников и других чиновников, которые встречают их дома» (там же: 261). Правительства легко становятся жертвами таких манипуляций и провоцируются на войны, поскольку стремятся сохранить репутацию надежных защитников своих подданных. Впрочем, провоцировать правителей обыкновенно нет никакой нужды: в надежде на военную добычу, которая может пополнить их собственную казну (пускай даже ценой разорения подданных), многие из них находят предлоги к войне сами и охотно обнажают свой меч, особенно, если думают, что он острее, чем у соседа. "Аругих естественных причин войны нет: нужда в пространстве земли подталкивает целую нацию к неизбежной войне, нужда отдельных людей дает войну произвольную» (там же: 259). 
«ПРОТИВОЕСТЕСТВЕННЫЕ» ВОЙНЫ: АМБИЦИИ, ГЕРОИЗМ, АЕМАГОГИЯ

Все прочие войны противоестественны.

Это войны, которые развязывают правители ради «выплаты старой забытой дани или признания титулов, которые, возможно, когда-то полагались побежденному королю, а теперь стали предметом притязаний наследников завоевателя, потерянных прав на королевства и провинции, защиты друзей и сторонников, выдуманные обиды и вообще всего, что угодно сделать предлогом» (там же: 264). В этом ряду стоят Троянская и первая Пуническая войны, борьба гвельфов и гиббелинов, крестовые походы.

Такие же войны, войны ради пустых амбиций, инициируют не только правительства, но и частные лица. Всевозможные мятежи подготавливаются бесчинствами коррумпированных «министров и чиновников, которые должны быть руками нации, но служат обществу лишь постольку, поскольку это в их интересах, занимаются стяжательством, не заботясь о том, что другие разоряются, а правительство страдает; [они] есть худшие враги, лучше бы им вовсе не рождаться, они - бесплодное дерево, которое не может принести доброго плода, люди чуждые благоразумию, справедливости и другим добродетелям, которые по праву зовутся главными, поскольку от них зависит безопасность и процветание всего людского рода» (там же: 282-283).

Однажды возникнув, мятеж разжигается руками «тщеславных глупцов, которые преследуют экстравагантные надежды, запутываются в хитросплетении рискованных обстоятельств, сбиваются силой страстей с пути, указанного разумом и здравым смыслом, и неизбежно заканчивают катастрофой, затем же, доведя себя до крайности, ропщут на Провидение за свои несчастья. Таких людей не так уж мало, и они всегда готовы примкнуть к любой партии в гражданских смутах либо для того, чтобы поправить свое положение, либо чтобы найти оправдание тому, до чего себя довели» (там же: 282). Весьма примечателен пример, приведенный Рэли, участником религиозных войн во Франции (на стороне гугенотов), для иллюстрации демагогии, разжигающей гражданскую войну. Это пример «свирепой войны, которая разразилась во Франции в царствование Франциска II, привела к самым варварским убийствам, разорениям и прочим бедствиям... и продолжалась усилиями нескольких могущественных людей, наделенных амбициозным и мятежным духом, которые обманули народ, нарядившись в маску религиозности, в действительности же им просто была нужна поддержка для осуществления своих подлинных планов. Ясно, что адмирах Колиньи советовал принцу Конде взять сторону гугенотов не только из-за того, что был увлечен их учением, но Аля того, чтобы составить партию и стать сильнее...» (там же: 284). Католическая партия, разумеется, использовала религиозный пыл своих сторонников в тех же целях.

Война - если речь не идет о войне естественной и неизбежной - не приносит народу ровным счетом ничего хорошего. Цена, которую приходится платить за войну людям, заведомо больше того, что они получают взамен. Чувство торжества, которое испытывает рядовой победитель, ложно, гибель прочих - бессмысленна: «что обмануло бедолаг, составлявших большую часть человечества, и заставило одних погибнуть ради целей, которые, будь они известны, вызвали бы у них отвращение? Что заставило других стать кровавыми исполнителями чужих амбиций? Горькая судьба быть убитым за то, за что вовсе не хотелось сражаться; однако очень мало солдат почили на ложе славы при иных обстоятельствах» (там же: 284).

Героическую сторону войны Рэли рассматривает достаточно пристально и скептически. Пунические войны создали уникальные образцы подлинного героизма - Ганнибала и Марка Атилия Регула, но они же породили множество подлецов и авантю- 
ристов: Ганнона, Центения Пенулу, Теренция Варрона и толпы их безмозглых сторонников в рядах Сената и народа обеих республик. Гражданские войны и вовсе не способны создавать героев: их участники становятся или мучениками, или палачами. Примеров подлинного торжества человеческого духа, ради которого стоило бы затевать войну, Рэли не приводит.

Разоблачение войны как практики, чуждой человеческой природе, - достаточно распространенный мотив ренессансной литературы (во время, близкое к Рэли, в этой связи можно указать хотя бы на примеры Эразма и Мора). Основой аргументации этой линии христианского гуманизма становится раскрытие мнимой рациональности и подлинно животного и бессмысленного характера мотивов к воинственной политике. Не менее, впрочем, распространены и диаметрально противоположные идеи, носителем которых является, например, Ф. Бэкон ( «внешняя война подобна теплу, вызванному движением тела, в высшей степени полезному для его здоровья. Аенивый и сонный мир ослабляет и изнеживает дух, развращает нравы» (Бэкон, 1977: 481); государству полезно наличие «таких законов и традиций, которые бы всегда могли предоставить ему законную причину или, по крайней мере, предлог для применения вооруженной силы» (там же: 480)).

Отправной точкой взглядов такого рода становится политический реализм в духе рассуждений Макиавелли, обосновывающего легитимность насилия и, в частности, войны в деле государственного строительства.

Анализируя феномен войны, Макиавелли, как известно, выносит его за скобки христианских представлений о морали. Война сама по себе не есть проявление пороков человеческой природы, она как таковая не есть зло: соответствующие черты она может приобретать, если вступает в противоречие с витальным и творческим началом политики. Оценка насилия, выведенная из сферы действия моральных оценок, подчинена у Макиавелли не этическим, а эстетическим критериям. В свою очередь, этические категории интерпретируются Макиавелли как инструмент контроля, как орудие в руках хорошего или дурного государственного деятеля; по отношению же к природе человека они рассматриваются не как ее элемент, а как некий побочный продукт политической манипуляции. Вне политического действия человек не морален и не аморален.

Рассуждения Рэли следуют макиавеллевской парадигме в ряде важных моментов. Политика и ее неотъемлемый элемент - вооруженное насилие анализируются Рэли с реалистических позиций. Он видит предпосылки войн в экономических и демографических процессах, во внутренней логике поиска и принятия политических решений; опираясь на соответствующие знания, он и предлагает их предотвращать. При этом моральное мировоззрение человека интерпретируется Рэли с совершенно иных позиций. В его трактате оно предстает не в качестве некоего эпифеномена политики, а как вполне реальный элемент человеческой природы. Моральная сторона поступков человека определяется противостоянием его разума (который и есть подлинно человеческое качество) и страстей, которые в конечном счете производны от его животных импульсов к обладанию вещами. Война аморальна, поскольку она и есть реализация этих импульсов; ее (возможные) естественные и неизбежные причины здесь ничего не меняют. Взгляд на войну под таким углом зрения был развит Эразмом Роттердамским в «Жалобе мира» и «Воспитании христианского государя»; в более широкой перспективе он связан с анализом проблемы самовластия в философии христианского гуманизма. 


\section{ЗАКАЮЧЕНИЕ}

Специфика взглядов Рэли состоит в своеобразном синтезе критики войны с позиций эразмовского гуманизма с политическим реализмом Макиавелли. Война не чужда человеческой природе вообще - делает вывод Рэли; но она бессмысленна и опасна для любого благоустроенного общества. Войну нельзя искоренить вовсе, но число ее случаев и ее масштабы можно значительно сократить, обладая знанием ее причин и скрытых механизмов.

\section{СПИСОК АИТЕРАТУРЫ}

Бэкон, Ф (1977) Сочинения : в 2 т. М. : Наука. Т. 1.568 с.

Аживелегов, А. К. (1943) Марло // История английской литературы / под ред. М. П. Алексеева и др. М. ; $\Lambda$. : Изд-во АН СССР. Т. І. Вып. 1. 383 с. С. 362-379.

Botero, G. A (1606) Treatise Concerning the Causes of the Magnificency and Greatness of Cities Divided into Three Books by Sig. Giovanni Botero in the ItalianTongue, now done into English by Robert Peterson. London, printed by T. P. for Richard Ockould. 108 p.

Clark, E. G. (1944) Ralegh and Marlowe; a Study in Elizabethan Fustian. New York, Fordham University Press. 488 p.

Evrigenis, I. D. (2013) Sir's Walter Raleigh Machiavelli // Machiavellian Encounters in Tudor and Stuart England. London and New York, Routledge Taylor and Francis Group. 218 p. P. 59-74.

Murrey, N. R. (2006) Austrian Perspective on the History of Economic Thought. V. I. Auburn, Alabama. : Ludwig von Mises Institute. 1084 p.

Ralegh, W. (1829) The Works of Sir Walter Ralegh. Vol. 8. Oxford, University Press. 792 p.

Ralegh, W. (1702) Three Discourses of Sr. Walter Ralegh. I. Of a War with Spain. II. Of the Original and Fundamental Cause of Natural, Arbitrary, and Civil War. III. Of Ecclesiastical Power. Published by Philip Ralegh, esq. his only grandson. London, Printed for B. Barker // The Internet Archive. URL: https://archive.org/details/threediscourseso00rale (дата обращения: 15.04.2018).

Reid, A. L. (2014) The Spectre of the School of Night: Former Scholarly Fictions and the Stuff of Academic Fiction [Электронный ресурс] // Early Modern Literary Studies, Special Issue 23 Christopher Marlowe: Identities, Traditions, Afterlives. URL: https://extra.shu.ac.uk/emls/journal/ index.php/emls/article/view/182/156 (дата обращения: 07.05.2018).

Stone, J. M. (1905) Studies From Court and Cloister Being Essays, Historical and Literary, Dealing Mainly With Subjects Relating to the XVIth and XVIIth Centuries. L. : Sands. 379 p.

Strathmann, E. A. (1951) Sir Walter Ralegh: a Study in Elizabethan Skepticism. N. Y. : Columbia University Press. 292 p.

Strathmann, E. A. (1965) A Note on Ralegh Canon// Times Literary Supplement, 13 April. P. 228.

Аата поступления: 30.08.2018г.

THE PHILOSOPHER IN MARLOWE'S CIRCLE: SIR WALTER RALEIGH
AND HIS TREATISE "DISCOURSE OF THE ORIGINAL
AND FUNDAMENTAL CAUSE OF NATURAL, ARBITRARY, AND CIVIL WAR"
V. V. MARKHININ
SURGUT STATE UNIVERSITY

The paper deals with the ideas of Sir Walter Raleigh (1552-1618), an English politician, soldier, thinker and a poet of Marlowian circle. The main subject of the research is Raleigh's theory of war which he made a starting point in the analysis of the dynamics of social life on the whole.

The author considers the nature of a possible influence that Raleigh's social and philosophical ideas could have had on Marlowe's worldview, analyses the ideas of Raleigh's philosophical and political treatises, reveals his role in the development of war problems in the philosophical literature of Renaissance. The key issues of Raleigh's philosophical oeuvre - an analysis of war phenomena, political manipulations, motives of political action - are in tune with Marlowe's drama plots. At the same 
time, the content of his discourses is fundamentally different from the ideas of Marlowe's libertinism, which were widespread in literature. In our opinion, the probable impact of Raleigh's philosophical ideas on Marlowe's worldview was typical of Christian humanism in the spirit of Erasmus of Rotterdam.

In his treatise, Raleigh assumes the anti-war position trying to reveal the prerequisites of wars and the conditions necessary to prevent them. Among wars, he points out "natural" ones, linked to the fight for indispensible resources. Some of them are inevitable, others inadvertent and, accordingly, can be prevented. The other type of wars has subjective, social and psychological prerequisites. Among those are civil and religious wars, which are unnatural and alien to reasonable human nature. The peculiarity of Raleigh's approach to the understanding of wars is a synthesis of Machiavellian political realism and Christian humanism.

The text of the author's speech at the First All-Russian Scientific Conference "Christopher Marlowe and His Oeuvre in Russian and World Culture: the Interdisciplinary Viewpoint", which was held in Moscow on the 22-23 June 2018.

Keywords: Renaissance philosophy; C. Marlowe; Walter Raleigh; philosophy of war

\section{REFERENCES}

Bekon, F (1977) Sochineniia: in 2 vol. Moscow, Nauka. Vol. 1. 568 p. (In Russ.).

Dzhivelegov, A. K. (1943) Marlo. In: Istoriia angliiskoi literatury / ed. by M. P. Alekseeva et al. Moscow, Leningrad, Izd-vo AN SSSR. Vol. I. Issue 1. 383 p. Pp. 362-379. (In Russ.).

Botero, G. A (1606) Treatise Concerning the Causes of the Magnificency and Greatness of Cities Divided into Three Books by Sig. Giovanni Botero in the ItalianTongue, now done into English by Robert Peterson. London, printed by T. P. for Richard Ockould. 108 p.

Clark, E. G. (1944) Ralegh and Marlowe; a Study in Elizabethan Fustian. New York, Fordham University Press. 488 p.

Evrigenis, I. D. (2013) Sir's Walter Raleigh Machiavelli. In: Machiavellian Encounters in Tudor and Stuart England. London and New York, Routledge Taylor and Francis Group. 218 p. P. 59-74.

Murrey, N. R. (2006) Austrian Perspective on the History of Economic Thought. V. I. Auburn, Alabama. : Ludwig von Mises Institute. 1084 p.

Ralegh, W. (1829) The Works of Sir Walter Ralegh. Vol. 8. Oxford, University Press. 792 p.

Ralegh, W. (1702) Three Discourses of Sr. Walter Ralegh. I. Of a War with Spain. II. Of the Original and Fundamental Cause of Natural, Arbitrary, and Civil War. III. Of Ecclesiastical Power. Published by Philip Ralegh, esq. his only grandson. London, Printed for B. Barker. The Internet Archive [online] Available at: https://archive.org/details/threediscourseso00rale (access date: 15.04.2018).

Reid, A. L. (2014) The Spectre of the School of Night: Former Scholarly Fictions and the Stuff of Academic Fiction. Early Modern Literary Studies, Special Issue 23 Christopher Marlowe: Identities, Traditions, Afterlives [online] Available at: https://extra.shu.ac.uk/emls/journal/index. $\mathrm{php} / \mathrm{emls} /$ article/view/182/156 (access date: 07.05.2018).

Stone, J. M. (1905) Studies From Court and Cloister Being Essays, Historical and Literary, Dealing Mainly With Subjects Relating to the XVIth and XVIItb Centuries. London, Sands. 379 p.

Strathmann, E. A. (1951) Sir Walter Ralegh: a Study in Elizabethan Skepticism. New York, Columbia University Press. 292 p.

Strathmann, E. A. (1965) A Note on Ralegh Canon. Times Literary Supplement, 13 April, p. 228.

Submission date: 30.08 .2018$.

Мархинин Василий Васильевич - кандидат философских наук, доцент кафедры политико-правовых дисциплин Сургутского государственного университета. Адрес: 628408, Россия, г. Сургут, ул. Энергетиков, д 8., каб. 207. Тел.: +7 (3462) 763-119. Эл. адрес: marhinin.basilio@ yandex.ru 
Markhinin Vasiliy Vasilyevich, Candidate of Philosophy, Associate Professor, Department of Political and Law Disciplines, Surgut State University. Postal address: 8, Energetikov St., Surgut, Russian Federation, 628408. Tel.: +7 (3462) 763-119 E-mail: marhinin.basilio@yandex.ru

DOI 10.17805/zpu.2018.4.20

\title{
Sergei Yutkevich's Othello Revisited: A View from the 21st Century*
}

\author{
B. N. GAYDIN \\ MOSCOW UNIVERSITY FOR THE HUMANITIES
}

The article summarizes and compares various opinions on Sergei Yutkevich's 1955 film "Othello" expressed both behind and beyond the Iron Curtain and after the collapse of the USSR. The author looks at these views through the prism of Yutkevich's own conception of the film he described in his book "Shakespeare and Cinema" (1973) and other publications. The author proposes a possible reason why Western Shakespearean scholars and film experts have not paid much attention to the work of the Soviet director, compared to "Hamlet" and "King Lear" directed by Grigori Kozintsev.

The main points of the article were presented at the panel "Shakespeare on the Soviet Screen" at the 9th European Shakespeare Research Association Congress "Shakespeare and European Theatrical Cultures: AnAtomizing Text and Stage" (July 27-30, Gdańsk, Poland).

Keywords: S. I. Yutkevich; "Othello"; film adaptations of "Othello"; W. Shakespeare; Shakespearean sphere; Shakespeare in contemporary cinema; Shakespeare in Russian culture; contemporary cinematography; Soviet cinema

\section{INTRODUCTION}

$A s$ is well-known, the only Russian filmmaker who is usuallycounted among the classic Shakespearean film directors along with Lawrence Olivier, Akira Kurosawa and Orson Welles is Grigory Kozintsev. He was certainly an erudite scholar. Otherwise, he would have hardly been able to shoot his famous Hamlet with Innokenty Smoktunovsky in the title role and to give full rein to his masterly skill so as to make a film that would later become a classic of the world cinematography.

It is not widely known that one of Kozintsev's friends since his adolescent years in Kiev1 was another Soviet director and artist Sergei Iosifovich Yutkevich. He was an avid Shakespearean too and knew Shakespeare's legacy as well as the history of its reception in the

* The article was prepared within the framework of the project "Shakespeare in Contemporary Russian Culture: The National and Global" with support from the Council for Grants of the President of Russian Federation (MK-1182.2017.6).

Статья подготовлена в рамках проекта «Шекспир в современной русской культуре: национальное и глобальное», осуществляемого при поддержке Совета по грантам Президента РФ (MK-1182.2017.6).

The Russian version of this article was published in Nauchnye trudy Moskovskogo gumanitarnogo universiteta journal in 2017 (Gaydin / Гайдин, 2017). The English version was substantially extended and amended. 